\title{
Image Processing dan Artifical Neural Network Untuk Mengenali Nomor Induk Kependudukan Pada KTP Sebagai Pendukung Layanan Mandiri di Kantor Desa
}

\author{
Jaroji $^{1}$, Rezki Kurniati ${ }^{2}$, Agustiawan ${ }^{3}$ \\ ${ }^{1,2}$ Program Studi Rekayasa Perangkat Lunak Politeknik Negeri Bengkalis \\ ${ }^{3}$ Program Studi Elektronika Politeknik Negeri Bengkalis \\ Jl. Bathin Alam, Sungai Alam, Bengkalis Riau, +62 (766) 24566 \\ e-mail: ${ }^{1}$ jaroji@ polbeng.ac.id, ${ }^{2}$ rezki@ $@$ polbeng.ac.id, ${ }^{3}$ agustiawan@
}

\begin{abstract}
Abstrak
Pelayanan prima yang cepat dan tepat harus diberikan oleh pemerintah desa kepada masyarakat. Namun kesan layanan birokrasi pemerintahan berbelit-belit sudah menjadi pemikiran kebanyakan masyarakat. Hal ini didasari atas fakta yang masyarakat alami sendiri ketika mereka memanfaatkan layanan di kantor desa. Sistem layanan mandiri dapat menjadi solusi untuk mengurangi jalur birokrasi yang dianggap berbelit-belit tersebut tanpa harus menghilangkan peran pihak-pihak terkait. Pada sistem layanan mandiri ini masyarakat dapat mengakses layanan seperti mengurus surat keterangan dan surat pengantar untuk berbagai keperluan. Untuk meminimalkan proses pengetikan oleh masyarakat digunakan image processing untuk mendapatkan data Nomor Induk Kepenedudukan (NIK) pada KTP. Image processing dilakukan dengan cara bileveling, smearing, penentuan baris dan ekstrasi citra digital ke citra biner yang menghasilkan vektor. Pola vektor tersebut di uji dengan jaringan syaraf tiruan metode backpropagation yang telah dilatih menggunakan 61 unit vektor data sampel. Hasilnya jaringan syaraf tiruan mampu mengenali (NIK) pada KTP, NIK tersebut dijadikan input pada system layanan mandiri.
\end{abstract}

Kata kunci: Pengolahan citra, Run Lenght Smearing Algorithm, Jaringan Syafat tiruan, Backpropation

\begin{abstract}
Excellent service should be provided promptly by the village government to the community. However, the impression of bureaucratic government service has become the most people thought. This is based on the facts that people themselves experience when they make use of the services in the village office. Self-service system can be a solution to reduce the bureaucratic path that is considered convoluted without having to eliminate the role of the parties concerned. In this self-service system the community can access services such as taking care of certificates and cover letters for various purposes. To minimize typing activities by community used image processing to obtain data population identification number on the ID card. Image processing is done by bileveling, smearing, line determination and extracting digital images into binary images that generate vectors. The vector pattern was tested with artificial neural network backpropagation method which has been trained using 61 vector units sample data. The result is artificial neural networks are able to recognize data population identification number on the ID card. The population identification number is used as inputs on the system self-service.
\end{abstract}

Keywords: Image processing, Run Lenght Smearing Algorithm, Articial neural network, Backpropagation. 


\section{Pendahuluan}

Pemerintah desa merupakan sub sistem dari sistem penyelenggaraan pemerintahan nasional ditingkat bawah yang langsung di bawah pemerintahan kabupaten [1], dalam Permendagri No. 84 tahun 2015, struktur pemerintah desa terdiri dari kepala desa, lembaga musyawarah desa, perangkat desa yang terdiri dari sekretaris desa, pelaksana wilayah dan pelaksana teknis [2]. Salah satu tugas dan layanan dari pemerintah desa adalah melakukan pendataan penduduk dan layanan untuk pembuatan Kartu Tanda Penduduk (KTP), Kartu Keluarga (KK), Surat Kelahiran, Surat Kematian, dan Surat Keterangan Pindah.

Teknologi informasi memberikan kemudahan bagi manusia. Pemanfaatanya dapat membantu pemerintah desa dalam melayani masyarakat. Bila melihat desa-desa yang ada di Kabupaten Bengkalis, pemanfaatan teknologi informasi ini belum maksimal. Selama ini sistem yang digunakan masih dalam bentuk sistem informasi manual, beberapa kendala didapatkan dalam penggunaan sistem manual ini seperti menyulitkan dan memperlambat dalam proses pengajuan usulan surat baru, perubahan maupun penghapusan data khususnya memberikan laporan data penduduk. Tidak sedikit juga masyarakat yang menganggap bahwa birokrasi dipemerintahan berbelit-belit dan menyulitkan. Hal ini didasari fakta yang mereka lihat ketika sedang mengurus administrasi kependudukan. Sementara masyarakat menginginkan pelayanan yang ramah, cepat dan efektif.

Sistem layanan mandiri (self service) dapat dijadikan solusi untuk memberikan layanan prima kepada masyarakat sekaligus memberikan edukasi penerapan teknologi informasi kepada masyarakat. Penggunaan self service technology yang disebut sebagai self-help, yang mengacu pada teknologi yang memungkinkan pelanggan untuk mempelajari, menerima informasi, melatih mereka sendiri dan memberikan pelayanan mereka sendiri. Keunggulan self service technology dapat ditinjau dari dua sisi yaitu perusahaan penyedia jasa dan pelanggan. Dari perusahaan penyedia jasa teknologi bisa menjadi kesempatan untuk mempercepat penyampaian jasa, ketepatan, customization, mengurangi biaya dan meningkatkan produktivitas. Bagi pelanggan self service technology juga memberikan beberapa keuntungan seperti penghematan waktu dan biaya, kontrol yang lebih tinggi pada pelayanan, memperpendek waktu tunggu, kemudahan lokasi, kesenangan dalam proses produksi dan kemudahan dalam penggunaaan [3].

Sistem layanan mandiri dapat digambarkan sebagai alat yang dapat dimanfaatkan oleh masyarakat dalam mengurus pembuatan surat keterangan (seperti surat kelahiran, surat kematian, surat keterangan pindah yang memerlukan kecermatan dan keakuratan data), surat pengantar dan pengurusan Kartu Keluarga (KK). Sistem layanan mandiri harus didesain agar dapat digunakan dengan mudah oleh masyarakat yang memiliki latar belakang pendidikan berbeda. Sebagai alat identifikasi data kependudukan digunakan Nomor Induk Kependudukan (NIK) yang tertera pada Kartu Tanda Penduduk (KTP), disinilah dibutuhkan image processing untuk menterjemahkan NIK tersebut menjadi citra biner yang selanjutnya diolah menggunakan jaringan syaraf tiruan dengan algoritma back propagation, sehingga NIK tersebut dapat dimengerti oleh sistem layanan mandiri, hal ini dilakukan untuk mengurangi aktifitas pengetikan oleh masyarakat. Sekaligus memberikan informasi bahwa penduduk yang bersangkutan memiliki dan membawa KTP. Setelah data kependudukan teridentifikasi oleh sistem, masyarakat dapat memilih layanan yang tertera pada layar, selanjutnya layanan akan diproses oleh sistem dan hasilnya akan diserahkan oleh pegawai kantor desa.

\section{Metode Penelitian}

Penelitian ini menggunakan beberapa metode image processing dan jaringan syaraf tiruan. Gambar di bawah ini merupakan tahapan-tahapan metode yang digunakan untuk mencapai hasil penelitian. 


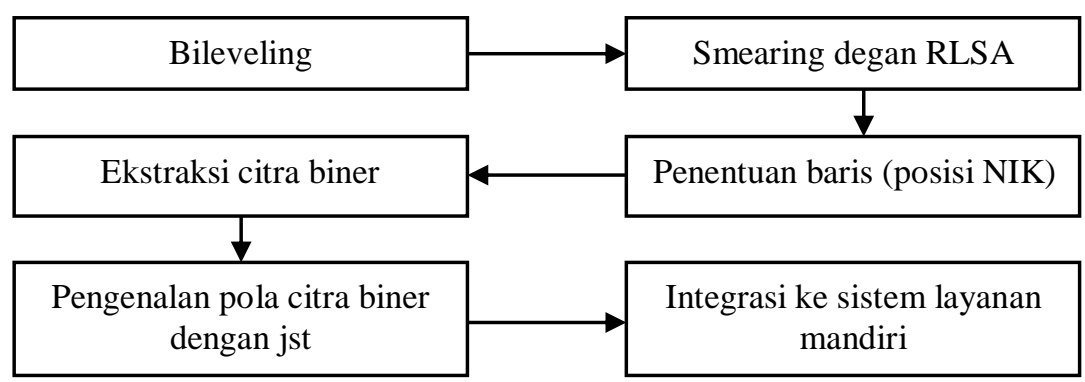

\subsection{Bileveling}

Gambar 1 Tahapan metode penelitian

Bileveling digunakan untuk merubah citra digital menjadi dua warna, yaitu hitam dan putih atau yang dikenal dengan citra biner [4]. Proses bileveling dilakukan dengan merubah citra digital menjadi abu-abu (grayscale), lalu ditentukan nilai ambang batas (thresold) warna. Selanjutnya setiap pixel citra dibaca untuk memperoleh warna dengan format rgb. Jika warna pixel di bawah ambang batas maka pixel warna tersebut dirubah menjadi hitam, sebaliknya jika warna pixel di atas ambang batas maka pixel warna dirubah menjadi warna putih. Gambar 2 berikut menunjukan proses bileveling yang terjadi.

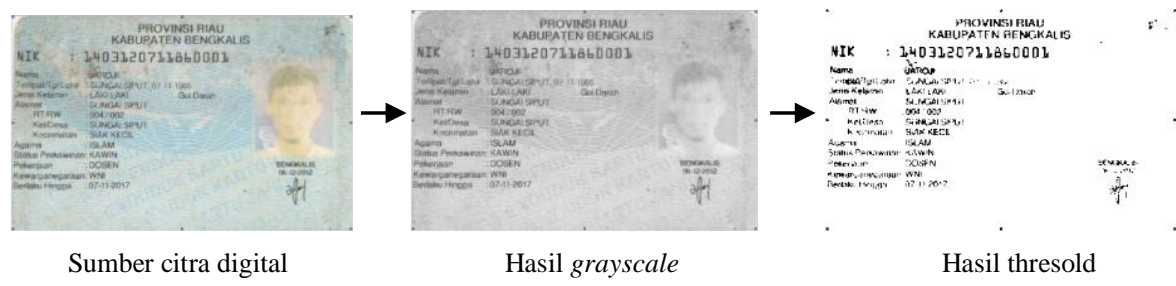

Gambar 2 Proses bileveling

\subsection{Run Length Smearing Algorithm (RLSA)}

Run-Length Smearing Algorithm (RLSA) atau biasa disebut dengan smearing merupakan salah satu metode yang berfungsi mencari lokasi teks dalam suatu gambar citra biner [5]. Dengan smearing, gambar akan diproses secara vertikal dan horisontal (scan-lines). Referensi [6] menyatakan bahwa cara kerja metode ini adalah dengan cara melakukan proses scan-lines pada citra digital secara vertikal dan horisontal. Setelah itu proses dilanjutkan dengan menentukan nilai batas bawah dan batas atas yang diperoleh dari jarak minimum dari angka yang satu ke angka lain yang bersebelahan yang dijadikan sebagai nilai batas bawah, sedangkan jarak maksimum dijadikan sebagai nilai batas atas. Nilai batas bawah dan atas dicari baik untuk horizontal (jarak antar angka) dan vertikal (tinggi angka). Setelah itu, dilakukan proses perhitungan piksel hitam yang berurutan dalam suatu garis. Jika jumlah dari piksel putih yang berurutan lebih kecil dari nilai batas bawah atau lebih besar dari nilai batas atas maka seluruh piksel yang berurutan tersebut diubah menjadi hitam. Sedangkan jika nilai piksel putih yang berurutan berada diantara nilai batas bawah dan atas maka seluruh piksel yang berurutan tersebut tidak diubah.

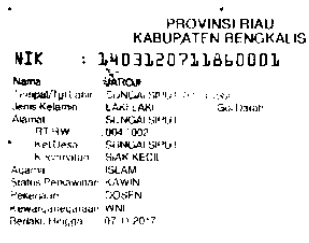

Citra bilevel

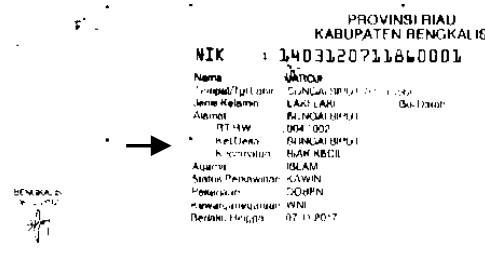

Smearing secara vertikal

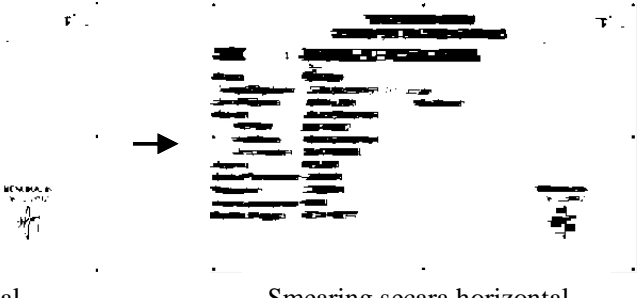

Smearing secara horizontal 
Nilai ambas batas yang ditetapkan antara proses smearing secara vertikal dan smearing secara horizontal berbeda. Hal ini dilakukan agar pada proses smearing vertikal blok pixel hitam yang menunjukan data provinsi, kabupaten, NIK dan seterusnya tidak saling tergabung.

\subsection{Penentuan Baris}

Setelah mendapatkan blok citra dengan pixel hitam, dilakukan pendeteksian baris dengan cara menjumlahkan pixel hitam dari kiri kekanan, jika jumlah pixel hitam lebih dari nilai ambang batas maka dianggap sebagai baris [4].

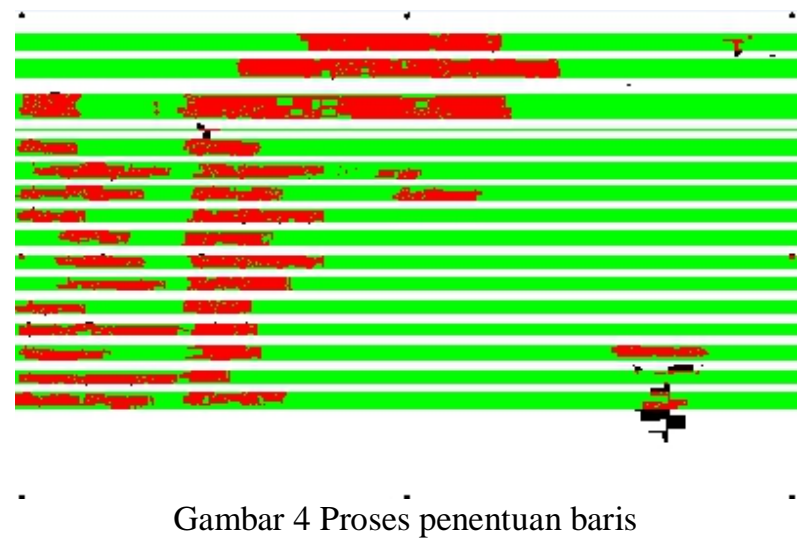

NIK terdapat pada baris ke tiga dengan cara membaca pixel hijau ketiga setelah pixel putih secara vertikal, sehingga diambil kordinat pixel pada baris tersebut sebagai acuan untuk mendapatkan pixel setiap digit dari NIK. Koordinat pixel tersebut digunakan untuk mendapatkan citra biner pada baris ketiga dari citra digital hasil smearing vertikal disertai dengan pemberian tanda jumlah pixel horizontal untuk setiap digit huruf atau angka.

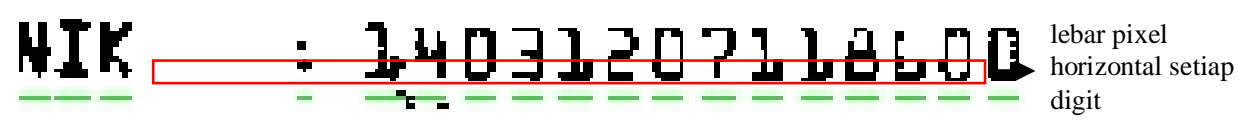

Gambar 5 Citra biner di baris ketiga

\subsection{Ekstraksi Citra Biner}

Citra biner merupakan citra digital dengan dua kemungkinan nilai pixel yaitu pixel-pixel objek bernilai 1 dan pixel-pixel latar belakang bernilai 0 [7]. Untuk mendapatkan citra biner dilakukan dengan cara pixel citra digital dibaca dari kiri kekanan dan atas ke bawah dengan mendeteksi pixel hijau setelah putih. Untuk digit NIK yang pertama, pixel citra dibaca berdasarkan pixel citra baris ketiga yang didapatkan dari metode sebelumnya dan pixel citra hijau setelah putih yang kelima. Pixel citra diekstrak ke matrik dengan ukuran $11 \times 15$. Hal yang sama juga dilakukan untuk digit angka berikutnya, sehingga didapatkan citra biner dalam bentuk vektor (matrik) dari semua digit NIK. Data vektor tersebut dijadikan sebagai input jaringan syaraf tiruan. 


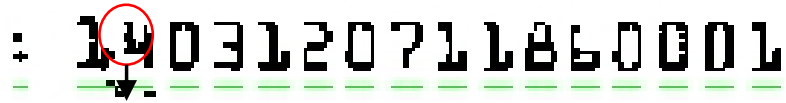 \\ $0,0,0,0,0,0,0,0,0,0,0$, \\ $0,0,0,1,1,1,0,0,0,0,0$, \\ $0,0,1,1,1,1,1,0,0,0,0$, \\ $0,0,0,0,0,1,1,0,0,0,0$, \\ $0,0,0,0,0,1,1,0,0,0,0$, \\ $0,0,0,0,0,1,1,0,0,0,0$, \\ $0,0,0,0,0,0,1,0,0,0,0$, \\ $0,0,0,0,0,1,1,0,0,0,0$, \\ $0,0,0,0,0,1,1,0,1,1,0$, \\ $0,0,0,0,0,1,1,0,1,1,0$, \\ $0,0,0,0,0,1,1,0,1,1,0$, \\ $0,0,0,0,1,1,1,1,1,1,0$ \\ $0,0,1,1,1,1,1,1,1,1,0$, \\ $0,0,0,0,0,0,0,0,1,0,0$, \\ $0,0,0,0,0,0,0,0,0,0,0$,
}

Gambar 6 Ilustrasi koversi citra digital ke vektor

\title{
2.5 Pengenalan Pola Citra Biner
}

\subsubsection{Artificial Neural Network}

Jaringan Saraf Tiruan (arficial neural network) atau di singkat JST adalah sistem yang mengumpulkan informasi tentang sampel oleh neuron buatan yang disatukan dengan cara yang sama seperti neuron di otak manusia; mereka mampu melakukan pengambilan keputusan dengan menggunakan apa yang mereka pelajari saat menghadapi masalah. Secara singkat, mereka adalah struktur jaringan yang dibuat dengan menghubungkan neuron buatan melalui berbagai geometri terkoneksi. Setelah membentuk struktur jaringan, input visual diklasifikasikan untuk mencapai kesimpulan [6]. JST dapat digambarkan sebagai model matematis dan komputasi untuk fungsi aproksimasi nonlinear, klasifikasi data, cluster dan regresi non parametric atau sebagai sebuah simulasi dari koleksi model saraf biologi [8].

\subsubsection{Fungsi Aktivasi Tanh}

Hyperbolic Tangent function atau yang sering disebut TANH merupakan salah satu fungsi aktivasi pada algoritma backpropagation. Fungsi ini umumnya lebih cepat mencapai konvergensi dibandingkan fungsi aktivasi sigmoid dan logistik dan dapat menghasilkan akurasi yang lebih tinggi [9].

\subsubsection{Metode Backpropagation}

Jaringan saraf tiruan backpropagation pertama kali diperkenalkan oleh Rumelhart, Hinton dan William pada tahun 1986, kemudian Rumelhart dan Mc Clelland mengembangkannya pada tahun 1988. Algoritma ini termasuk dalam supervised learning dimana ciri dari metode ini adalah meminimalkan error pada output yang dihasilkan oleh jaringan. Algoritma backpropagation untuk neural network umumnya diterapkan pada jaringan berlapis banyak (multilayer) [10]. Backpropagation merupakan algoritma pembelajaran yang terawasi dan biasanya digunakan oleh perceptron dengan banyak lapisan untuk mengubah bobot-bobot yang berhubungan dengan neuron-neuron yang ada pada lapisan tersembunyinya. Algoritma backpropagation menggunakan error output untuk mengubah nilai bobot-bobotnya dalam arah mundur (backward). Untuk mendapatkan error ini, tahap perambatan maju (forward propagation) harus dikerjakan terlebih dahulu [8]. Referensi [11] juga menyatakan backpropagation adalah metode penurunan gradien untuk meminimalkan kuadrat error keluaran. Ada tiga tahap yang harus dilakukan dalam pelatihan jaringan, yaitu tahap perambatan maju (forward propagation), tahap perambatan balik (backpropagation), dan tahap perubahan bobot dan bias. 
Pada dasarnya, pelatihan dengan metode backpropagtion terdiri atas tiga langkah, yaitu sebagai berikut [7]:

1. Data dimasukkan ke input jaringan (feedforward)

2. Perhitungan dan propagasi balik (backpropagation) dari error yang bersangkutan

3. Pembaharuan (adjustment) bobot dan bias.

\subsubsection{Arsitektur Jaringan Syaraf Tiruan}

Jaringan syaraf tiruan dengan metode backpropagation terdiri dari tiga lapisan, yaitu lapisan input, tersembunyi dan output. Pemilihan arsitektur yang tepat merupakan salah satu faktor keberhasilan target yang hendak dicapai [8]. Pada penelitian jaringan terdiri atas 165 unit input, $n$ unit lapisan tersembunyi dan 1 unit lapisan output. Jumlah lapisan tersembunyi ditentukan sendiri oleh user melalui cara percobaan konvergensi terbaik (trial and error) sampai diperoleh hasil konvergensi pelatihan yang paling baik (jumlah epoch terkecil). Gambar berikut ini menggambarkan arsitektur jaringan yang dipilih.

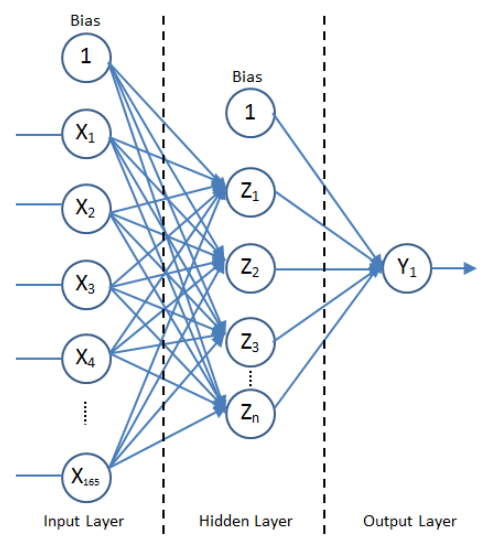

Gambar 7 Arsitektur jaringan syaraf tiruan multi layer

\subsubsection{Data Training dan Data Testing}

Data pelatihan (training) merupakan data yang digunakan untuk melatih jaringan agar mengenal pola yang diinginkan. Data pelatihan terdari dari vektor matrik 11x15 yang mewakili digit angka dari 0 sampai dengan 9 dengan jenis font yang sesuai dengan NIK, data pelatihan didapatkan dari beberapa sampel KTP. Data pengujian (testing) merupakan data yang digunakan untuk menguji apakah jaringan saraf mampu mengenali pola yang diinginkan. Data pengujian berupa NIK dari KTP selain sampel data training dan data NIK bagian dari data training.

\section{Hasil dan Pembahasan}

Sistem yang telah diusulkan dibuat dengan dengan bahasa pemrograman PHP versi 7. Image Processing, pelatihan dan pengujian Jaringan Syaraf Tiruan di jalankan pada komputer dengan spesifikasi CPU Intel Core i5 dan memory 4 GB serta kamera 13 Mega Pixel.

\subsection{Hasil Pengolahan Citra}

Input dari pengolahan citra adalah KTP yang telah capture menggunakan kamera, citra digital tersebut melalui beberapa tahapan seperti resizing menjadi 400x252 pixel, bileveling, smearing, penentuan baris dan ekstrasi citra ke data biner (vektor). Tabel 1 berikut menunjukan hasil dari beberapa data sampel.

Tabel 1. Hasil pengolahan citra digital

\begin{tabular}{|c|c|c|c|}
\hline$\frac{\text { No }}{1}$ & Citra Asli* & Image Processing $*$ & Vektor $* *$ \\
\hline \multirow[t]{2}{*}{1} & NIK : 24031207118 & Bileveling: & Digit 1: \\
\hline & & HIK : : 40J120P1LB & $\begin{array}{l}0,0,0,0,0,0,0,0,0,0,0,0,0,0,1,1,1,0,0,0,0 \\
0,0,0,1,1,1,1,1,0,0,0,0,0,0,0,0,0,1,1,0,0\end{array}$ \\
\hline
\end{tabular}




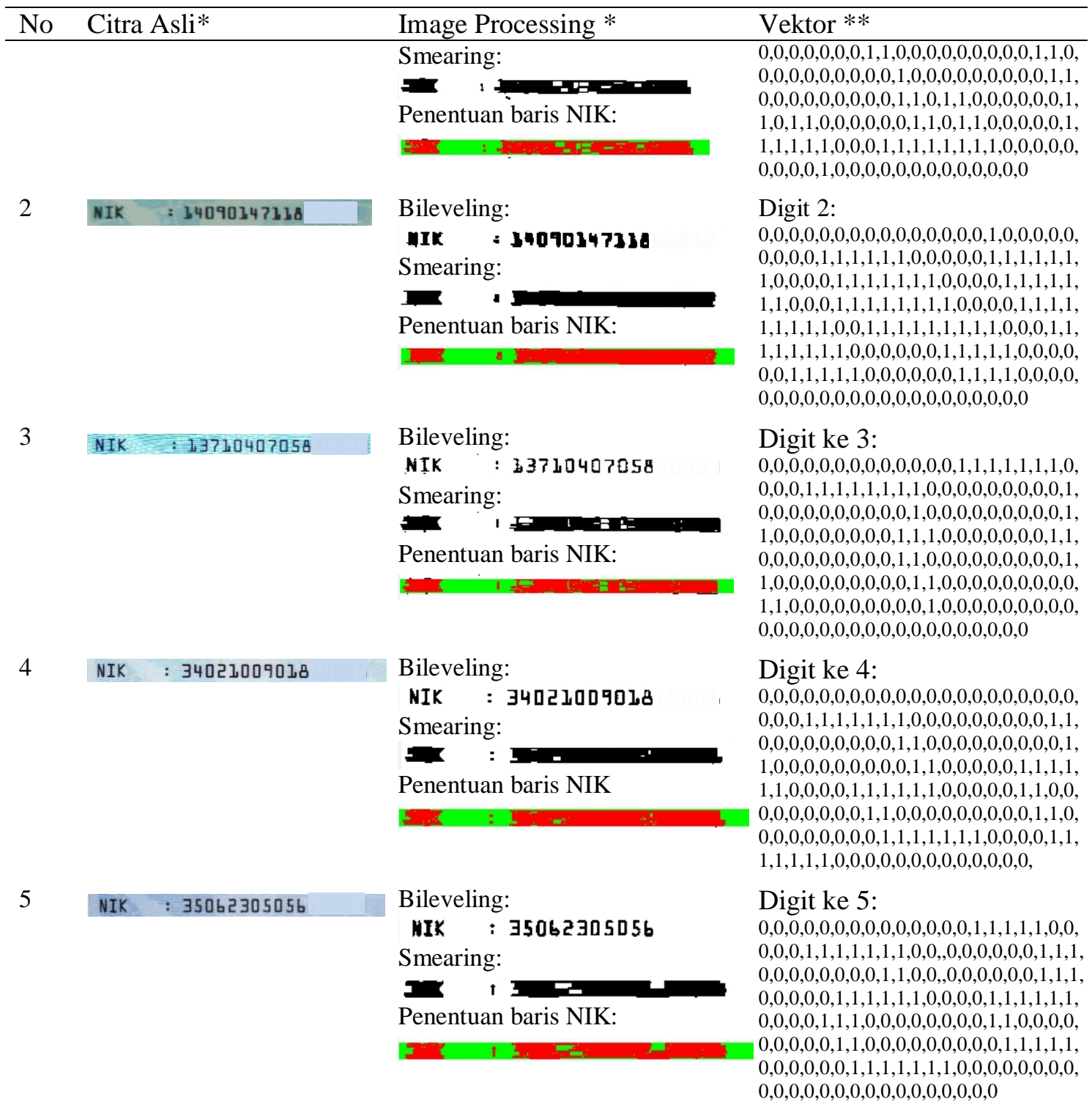

* Hanya ditampilkan baris NIK dan 5 digit terakhir disamarkan dengan alasan privasi ** Hanya ditampilkan untuk 1 vektor karena jumlah vektor yang banyak

Image processing dengan smearing tergantung pada kualitas fisik KTP dan kualitas citra digital yang didapatkan dari kamera. Sumber citra digital yang buruk akan menyebabkan proses segmentasi tidak sesuai harapan. Gambar 7 berikut memperlihatkan hasil segmentasi dengan smearing yang tidak sempurna.

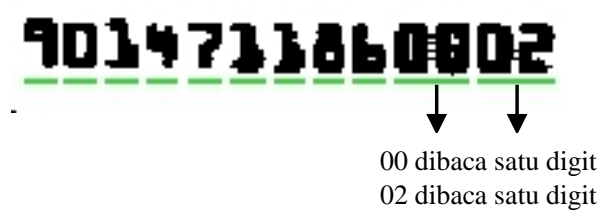

Gambar 8 Hasil smearing yang tidak sempurna 


\subsection{Hasil Training Jaringan Syaraf Tiruan}

Data pelatihan terdiri dari 61 unit vektor 11x15 dengan arsitektur jaringan 164 unit lapisan input, 10 unit lapisan tersembunyi dan satu unit keluaran. Laju pembelajaran (learning rate) ditetapkan sebesar 0.1, maksimal epoch sebesar 1000 dan MSE sebesar 0.002. Hasil training menunjukan semua data pelatihan dikenali oleh jaringan syaraf tiruan pada epoch ke 489. Berikut hasil pelatihan 10 data training dari 61 unit vektor data pelatihan yang dikenali oleh jaringan:

Tabel 2. Hasil training data pelatihan dengan JST

\begin{tabular}{|c|c|c|c|}
\hline No. & Data Training & Target & Hasil JST \\
\hline 1 & $\begin{array}{l}0,0,0,0,0,0,0,0,0,0,0,0,1,1,1,1,1,0,0,0,0,0,0,1,0,1,1,1,0,0,0,0,0,0,0,0,0,1,1,0,0,0,0,0,0,0, \\
0,0,1,1,0,0,0,0,0,0,0,0,0,0,1,0,0,0,0,0,0,0,0,0,1,1,0,0,0,0,0,0,0,0,0,1,1,0,0,1,0,0,0,0,0,0, \\
1,1,1,1,1,0,0,0,0,0,0,1,1,0,1,1,0,0,0,0,0,0,1,1,1,1,1,0,0,0,1,1,1,1,1,1,1,1,0,0,0,1,1,1,1,1 \\
1,1,1,0,0,0,0,0,0,0,0,0,0,0,0,0,0,0,0,0,0,0,0,0,0,0,0\end{array}$ & 0,1 & 0,09906 \\
\hline 2 & $\begin{array}{l}0,0,0,1,1,1,1,0,0,0,0,0,0,1,1,1,1,1,1,0,0,0,0,0,1,1,1,1,1,1,1,0,0,0,0,0,0,0,0,1,1,1,0,0 \\
0,0,0,0,0,0,0,1,1,0,0,0,0,0,0,0,0,1,1,1,0,0,0,0,1,1,1,1,1,1,1,0,0,0,1,1,1,1,1,1,1,0,0,0 \\
0,1,1,1,0,0,0,0,0,0,0,0,1,1,1,0,0,0,0,0,0,0,0,1,1,1,0,0,0,0,0,0,0,0,1,1,1,1,1,1,1,0,0,0 \\
0,1,1,0,1,1,0,1,0,0,0,0,0,0,0,0,0,0,0,0,0,0,0,0,0,0,0,0,0,0,0,0,0\end{array}$ & 0,2 & 0.19934 \\
\hline 3 & $\begin{array}{l}0,0,0,0,0,0,0,0,0,0,0,0,1,1,1,1,1,1,1,0,0,0,0,1,1,1,1,1,1,1,1,0,0,0,0,0,0,0,0,1,1,1,0,0 \\
0,0,0,0,0,0,1,1,1,0,0,0,0,0,0,0,0,1,1,1,0,0,0,0,0,1,1,1,1,1,0,0,0,0,0,1,1,1,1,1,1,0,0,0 \\
0,0,0,0,0,0,1,1,1,0,0,0,0,0,0,0,0,1,1,1,0,0,0,0,0,0,0,0,1,1,1,0,0,0,1,1,1,1,1,1,1,0,0,0\end{array}$ & 0,3 & 0.30092 \\
\hline 4 & $\begin{array}{l}0,0,0,0,0,0,0,0,0,0,0,0,1,1,0,0,0,0,0,0,0,0,0,1,1,0,0,0,0,1,0,0,0,0,1,1,0,0,1,1,1,0,0,0 \\
0,1,1,1,0,1,1,1,0,0,0,0,1,1,1,0,1,1,0,0,0,0,0,1,1,1,0,1,1,1,0,0,0,0,1,1,1,1,1,1,1,0,0,0 \\
0,1,1,0,1,1,1,1,0,1,0,0,0,0,0,0,1,1,1,0,0,0,0,0,0,0,0,1,1,1,0,1,0,0,0,0,0,0,1,1,1,0,0,0\end{array}$ & 0,4 & 0.40192 \\
\hline 5 & $\begin{array}{l}0,0,0,0,0,0,0,0,0,0,0,0,0,1,1,1,1,1,1,0,0,0,0,0,1,1,1,1,1,0,0,0,0,0,0,1,1,1,0,0,0,0,0,0 \\
0,0,1,1,0,0,0,0,0,0,0,0,0,1,1,1,0,0,0,0,0,0,0,0,1,1,1,1,1,0,0,0,0,0,0,1,1,1,1,1,1,0,0,0 \\
0,0,0,0,0,0,1,1,0,0,0,0,0,0,0,0,0,1,1,0,0,0,0,1,0,0,0,0,1,1,0,0,0,0,1,1,1,1,1,1,1,0,0,0 \\
0,1,1,1,1,1,1,0,0,0,0,0,0,0,0,0,0,0,0,0,0,0,0,0,0,0,0,0,0,0,0,0,0\end{array}$ & 0,5 & 0.49996 \\
\hline 6 & $\begin{array}{l}0,0,0,0,0,0,0,0,0,0,0,0,0,1,1,0,0,0,0,0,0,0,0,1,1,1,0,0,0,0,0,0,0,0,1,1,1,0,0,0,0,0,0,0 \\
0,1,0,1,0,0,0,0,0,0,0,0,1,1,1,0,0,0,0,0,0,0,0,1,1,1,0,0,0,0,0,0,0,0,1,1,1,1,1,1,1,0,0,0 \\
0,1,0,1,1,1,1,1,1,0,0,0,1,1,1,0,0,1,1,1,0,0,0,1,0,1,0,0,1,1,1,0,0,0,1,1,1,1,1,1,1,1,0,0\end{array}$ & 0,6 & 0.59965 \\
\hline 7 & $\begin{array}{l}0,0,0,0,0,0,0,0,0,0,0,0,1,1,0,1,1,1,1,0,0,0,0,1,1,1,1,1,1,1,1,0,0,0,0,0,0,0,0,0,1,0,0,0 \\
0,0,0,0,0,0,0,1,0,0,0,0,0,0,0,0,0,1,1,0,0,0,0,0,0,0,0,1,1,1,0,0,0,0,0,0,0,1,1,0,0,0,0,0 \\
0,0,0,0,1,1,0,0,0,0,0,0,0,0,0,1,1,0,0,0,0,0,0,0,0,0,1,1,0,0,0,0,0,0,0,0,0,1,1,0,0,0,0,0\end{array}$ & 0,7 & 0.70003 \\
\hline 8 & $\begin{array}{l}0,0,0,0,0,0,0,0,0,0,0,0,0,0,1,0,1,1,1,0,0,0,0,0,0,1,1,1,1,1,1,0,0,0,0,0,1,1,0,0,1,1,1,0 \\
0,0,0,1,1,0,0,1,1,1,0,0,0,0,1,1,1,1,1,1,1,0,0,0,1,1,1,1,1,1,1,1,0,0,0,1,1,1,1,1,1,1,1,0 \\
0,1,1,1,0,0,0,0,1,0,0,0,1,1,1,0,0,0,0,1,1,0,0,1,1,1,0,0,0,0,0,1,0,0,0,1,1,1,1,1,1,1,1,0\end{array}$ & 0,8 & 0.80029 \\
\hline 9 & $\begin{array}{l}0,0,0,0,0,0,0,0,0,0,0,0,1,0,1,1,0,1,1,0,0,0,0,1,1,1,1,1,1,1,1,0,0,0,1,1,1,0,0,1,1,1,0,0 \\
0,1,1,1,0,0,1,1,1,0,0,0,1,1,1,1,1,1,1,1,0,0,0,0,1,1,1,1,1,1,1,0,0,0,0,0,0,0,0,1,1,1,0,0 \\
0,0,0,0,0,0,1,1,1,0,0,0,0,0,0,0,0,1,1,1,0,0,0,0,0,0,0,0,1,1,1,0,0,0,0,0,0,0,0,1,1,0,0,0\end{array}$ & 0,9 & 0.89486 \\
\hline 10 & $\begin{array}{l}0,0,0,0,0,0,0,0,0,0,0,0,0,1,1,1,1,1,1,0,0,0,0,1,0,1,1,1,1,1,1,0,0,0,1,1,1,0,0,1,1,1,0,0 \\
0,1,1,1,0,0,0,1,1,0,0,0,1,1,1,0,0,1,1,1,0,0,0,1,1,1,0,0,0,1,1,0,0,0,1,1,1,0,0,0,1,1,0,0 \\
0,1,1,1,0,0,0,1,1,0,0,0,1,1,1,0,0,1,1,1,0,0,0,1,1,1,0,0,1,1,1,0,0,0,1,1,1,1,1,1,1,1,0,0\end{array}$ & 0,0 & -0.00090 \\
\hline
\end{tabular}

Hasil jst di atas dikalikan dengan 10 untuk mendapatkan nilai dari 0 sampai dengan 9. Jika hasil jst minus maka dikali dengan -1 untuk mendapatkan bilangan positif.

\subsection{Hasil Pengujian Jaringan Syaraf Tiruan}

Jaringan yang telah dilatih di uji dengan data pengujian, tabel 2 berikut menunjukan hasil pengujian jaringan syaraf tiruan:

Tabel 3 Pengujian jaringan syaraf tiruan

\begin{tabular}{lll}
\hline No. & Citra $*$ & Hasil pengenalan pola \\
\hline 1 & NIK : 240312071186 & 140312071186 \\
2 & NIK $: 350623050565$ & 411516380744 \\
\hline
\end{tabular}




\begin{tabular}{llll}
3 & NIK $: 340210090181$ & 340210090181 \\
4 & NIK $: 137104070588$ & 137104070588 \\
5 & NIK $: 331,09200680$ & 331109200680 \\
\hline
\end{tabular}

* Hanya ditampilkan baris NIK dan 5 digit terakhir disamarkan dengan alasan privasi

Berdasarkan hasil pengujian jaringan, tidak semua digit NIK dapat dikenali oleh jaringan syaraft tiruan. Dari lima pengujian di atas terdapat empat data NIK yang dikenali oleh JST, keempat data tersebut telah dilatih dengan JST. Sedangkan satu data NIK tidak dikenali oleh JST karena data NIK ini belum dilatih dengan JST.

\subsection{Pendukung Layanan Sistem Mandiri di Kantor Desa}

Proses image processing dan JST untuk mengenali citra NIK pada KTP menjadi angka menghasilkan data NIK yang dapat dimanfaatkan untuk mengakses sistem layanan mandiri di kantor desa. Sistem ini didesain agar penduduk dapat mengurus kebutuhan administrasi seperti mengurus surat keterangan tidak mampu, surat keterangan kurang mampu, surat keterangan penghasilan, surat keterangan domisili, surat keterangan lainnya secara mandiri melalui computer standing, hal ini dapat meminimalkan pengetikan. Penduduk harus meletakan KTP pada slot yang telah disediakan, kemudian sistem akan memindai KTP melalui kamera. Citra digital tersebut diolah dengan image processing untuk menghasilkan vektor, selanjutnya vektor dikenali polanya oleh jaringan syaraf tiruan untuk mendapatkan NIK. Setelah NIK didapatkan penduduk yang terdaftar dapat mengakses sistem layanan mandiri tersebut.

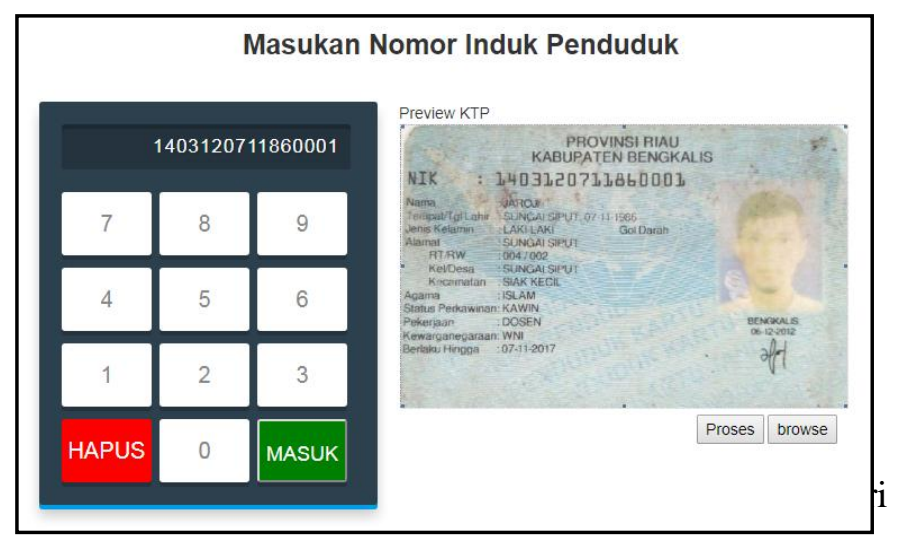

\section{Kesimpulan}

Berdasarkan hasil dari analisis dan tahapan pengujian image processing dan jaringan syaraf tiruan untuk mengeali pola NIK dapat disimpulkan hal-hal berikut:

a. Keberhasilan konversi citra ke vektor yang diinginkan bergantung pada kualitas fisik citra (KTP) dan kualitas hasil akuisisi citra digital. Semakin baik kondisi fisik citra dan proses akuisisi yang baik maka semakin sesuai pula vektor yang didapatkan, begitu juga sebaliknya. Hal ini ditunjukan pada gangguan derau (noise) yang mengakibatkan 2 digit angka NIK terbaca menjadi 1 digit angka.

b. Jaringan syaraf tiruan yang telah dilatih dengan MSE yang kecil yaitu 0.002 masih belum mampu mengenali semua data pengujian. Hal ini disebabkan hasil vektor untuk pengujian memiliki perbedaan besar dengan vektor data training.

c. Untuk memberikan layanan prima kepada masyarakat sistem layanan mandiri harus mampu mengidentifikasi NIK dengan akurat, sehingga memudahkan masyarakat untuk mengakses layanan mandiri di kantor desa. 


\section{Daftar Pustaka}

[1] Suwarno, Joni. Kualitas Pelayanan Pemerintahan Desa (Studi Pelayanan Ktp Dan Kk Di Desa Teluk Kepayang Kecamatan Kusan Hulu Kabupaten Tanah Bumbu). Jurnal Ilmu Politik dan Pemerintahan Lokal. 2012; Vol 1 (2): 184 - 212

[2] Kementrian Dalam Negeri, Susunan Organisasi dan Tata Kerja Pemerintah Desa, Permendagri nomor 84 tahun 2015

[3] Howard, Melanie. Worboys, Caroline. Self-Service - a contradiction in terms or costumer-led choice?. Journal of Consumer Behavior. 2003; Vol 2 (4): 382 - 392

[4] Widodo, Sugeng. Optical Caracter Ricognition for Indonesian Electrical Id-Card Image. IC-ITECH. 2014; vol : 225-232

[5] Lesdiani, Mety. Pengenalan Plat Nomor Kendaraan Menggunakan Metode Run Length Smearing dan K-earestneighbour. APOTEMA: Jurnal Program Studi Pendidikan Matematika, 2017. Vol 3 (2) : $58-68$

[6] Staup, Selva, et. Al. Artificial Neural Network and Agiltiy. Procedia - Social and Behavioral Sciences 195. 2015; 1477 - 1485

[7] Kumeseh, Max R, dkk. Segmentasi Citra Digital Ikan Menggunakan Metode Thresholding. Jurnal Ilmiah Sain. 2013; Vol 13 (1) : 74 - 79

[8] Tanjung, DH. Jaringan Syaraf Tiruan dengan Backpropagation untuk Mendeteksi Penyakit Asma. Citec Journal. 2014-2015; Vol 2 (1): 28-37

[9] Wibawa, Made Satria. Pengaruh Fungsi Aktivasi, Optimasi dan Jumlah Epoch Terhadap Performa Jaringan Syaraf Tiruan. Jurnal Sistem dan Informatika. 2017; Vol 11 (2): 167174

[10] Sakinah, Nabila Putra, dkk. Prediksi Jumlah Permintaan Koran Menggunakan Motode Jaringan Syaraf Tiruan Backpropagation. 2017; Vol 2 (7): 2612 - 2618

[11] Lestari, Novia. Van FC, Lucky Lhaura. Implementasi Jaringan Syaraf Tiruan Untuk Menilai Kelayakan Tugas Akhir Mahasiswa (Studi Kasus di AMIK Bukittinggi). 2017; Vol 8 (1): $10-24$ 